\title{
Assessment of Soil Loss in a Typical Ungauged Dam Catchment using RUSLE Model (Maruba Dam, Kenya)
}

\author{
Allois K. Luvai ${ }^{*} \quad$ John P.O. Obiero ${ }^{2} \quad$ Christian T. Omuto $^{2}$ \\ 1. School of Agricultural Sciences and Agribusiness, Pwani University, P.O Box 195 - 80108, Kilifi, \\ Kenya \\ 2. School of Engineering, University of Nairobi, P.O Box 30197 - 00100, Nairobi, Kenya \\ * E-mail of the corresponding author: kioko.allois@gmail.com; 1.allois@pu.ac.ke
}

\begin{abstract}
Soil erosion is a serious land degradation problem which nations all over the world are struggling with. It has affected many river catchments most of which are very dynamic and have become quite vulnerable due to human influence. As such, the functionality of the ecosystem has been largely compromised. Soil erosion has been reported as an expensive problem to remedy and therefore numerous of efforts have shifted to its prevention. This has called for estimation of soil loss which has been adequately achieved by use erosion models over the past. One such model is the Revised Universal Soil Loss Equation (RUSLE) which has been applied at catchment level. Maruba dam catchment has become very unhealthy due to the unsustainable modifications of the terrain. This is evident at the rate at which the dam is losing its storage capacity due to sedimentation. The current situation in the dam formed the basis for this study. Information on soil loss within the catchment is missing and as such decision makers do not have a basis for initiating soil and water conservation plans. The methodological framework for this study was the use of RUSLE model integrated in a GIS framework. The parameters of the model were derived using GIS and RS tools. The study revealed that soil loss ranged between 0 and $29 \mathrm{tha}^{-1} \mathrm{yr}^{-1}$ and this explains why the dam if silting up at a fast rate. With this set of information on soil loss, the health of the catchment would be adequately restored and this would save the dam from unwarranted sedimentation.
\end{abstract}

Keywords: Soil erosion, catchment, RUSLE, sedimentation, GIS

DOI: $10.7176 / \mathrm{JEES} / 11-16-06$

Publication date:June $30^{\text {th }} 2021$

\section{Introduction}

Soil erosion is a serious land degradation problem which extends all over the world, (Girmay et al., 2020). It is a more complex phenomenon due to the various natural processes which are involved, (Onyando et al., 2005). Ideally, soil erosion is a three phase phenomenon which involves detachment, transport and deposition of soil particles (Merritt et al., 2003; Benavidez et al., 2018). Soil loss due to the effect of water has been identified the worst form of land degradation especially in third world countries, (Sujatha \& Sridhar, 2018; Beyene, 2019). Water erosion is evident on the surface of land where widespread loss of soil has been noted, (Gitas et al., 2009). This process has been accelerated by human activities where soil loss has exceeded the rate of soil formation within a given area, (Wolka et al., 2015). Besides, climate change plays a significant role in acceleration of soil loss. This loss of soil has had adverse effects on all natural ecosystems and has since compromised their functionality, (Panagos et al., 2015).

Soil erosion impacts are worst pronounced in developing countries because farmers rely mostly on intrinsic properties of lands and they are unable to restore the fertility of soils due to the cost of inputs. In the Kenyan situation for instance, agriculture remains an important driver of the economy, (Onyando et al., 2005) but this would be possible if the soils are of good quality, (Fleitmann et al., 2007). However, about $75 \%$ of the Kenyan soils are reported to be environmentally fragile, (Fwamba et al., 2017). This has been attributed to soil erosion which has led to severe degradation of agricultural lands thereby reducing the country's capacity to produce and increasing the occurrence of some natural hazards, (Biamah, 1997). Dregne (1990) reported that more than $20 \%$ of Kenyan land has been subjected to permanent soil loss by water erosion. This is an indication that soil erosion is a serious environmental threat to the Kenyan soils as statistics show that soil loss in the country is way beyond the permissible annual rates of between 2.2 and $10 \mathrm{t} \mathrm{ha}^{-1} \mathrm{yr}^{-1}$, (Angima et al., 2003).

Land degradation assessment in developing countries has been constrained by lack of data and finances to facilitate assessment efforts, (Hammad, 2009). This makes it hard for the implementation of conservation plans especially in high erosion risk watersheds, (Beyene, 2019). On the other hand, soil erosion experiences a high spatial and temporal variation (Onyando et al., 2005) and therefore it is very useful to obtain correct information at the point 
of occurrence in order to facilitate planning for conservation measures, (Pandey et al., 2015; Wolka et al., 2015). Further, soil erosion process is complicated by the interplay between physical and hydrological factors (Onyando et al., 2005) and as result, soil conservation practices and consistent estimates for soil erosion rates in watersheds remain a big challenge for any soil erosion study. Thus, soil loss and even sediment yield have been better estimated with the use of hydrological models which have comprehensive geospatial sets of data especially on both biophysical as well as hydrological factors which cause soil erosion, (Benavidez et al., 2018; Woldemariam \& Harka, 2020). As such reasonable estimates are obtained with soil erosion models, (Onyando et al., 2005).

The sustenance of the ecology and economic development calls for prediction of the spatial variation and magnitude of soil erosion in order to plan for appropriate conservation measures, (Gelagay \& Minale, 2016; Sujatha \& Sridhar, 2018). Further, soil erosion has been pronounced as global hazard and therefore a relevant approach is required for the estimation of the spatial extend of soil erosion, (Wolka et al., 2015). All over the world, scientists have applied related approaches and even models through which soil erosion has been estimated and related processes studied, (Wolka et al., 2015). These approaches differ in terms of complexity, process, data requirements and application. A model is chosen on the basis of the study objectives, characteristics of the catchment, data availability and efficiency of the model.

Soil erosion models have been categorized as physical, conceptual and empirical and this has been on the basis of the physical simulation process as well as data requirements, (Merritt et al., 2003; Sujatha \& Sridhar, 2018). Whereas physical models are sophisticated and suited in numerous environmental applications, they are quite complex and data demanding, (Sujatha \& Sridhar, 2018). On the other hand, parameters involved in conceptual models have limited scope when it comes to interpreting physical processes, (Sujatha \& Sridhar, 2018). Physical soil erosion processes are better modeled using temporal data such as rainfall data with high resolution, infiltration rates in addition to saturated hydraulic conductivity. However, when such data is not available empirical models are preferred especially on regional scales and in preliminary assessment, (Sujatha \& Sridhar, 2018). Empirical models have been widely used as opposed to physical models because they require minimum amounts data and they are easy to apply in estimation of annual soil loss at both regional and global levels, (Efthimiou et al., 2014).

The USLE (Universal Soil Loss Equation) is one such empirical model which has been widely accepted and applied to estimate soil loss on an annual basis, (Wischmeier \& Smith, 1978). It is described as simple and robust in addition to representing a standard approach. In the event that there are no measurements available, the USLE serves as the most efficient method for soil loss assessment, (Efthimiou et al., 2014). Renard et al. (1991) developed the Revised Universal Soil Loss Equation (RUSLE) model which has the capability of incorporating additional research where an elaborate understanding of soil erosion process was developed. However, the basic form of the USLE equation remained the same with only a few modifications in some soil erosion factors changing, (Efthimiou et al., 2014).

Soil erosion is a disturbing problem within Maruba dam catchment and its consequences are so severe. However, there have been no studies which aim to quantify soil erosion rates within the catchment. There is need to have specific information on soil erosion within the catchment in order to inform decision making with regards to Maruba dam reservoir which is heavily silted. The purpose of this study was to predict the rates of soil loss within Maruba dam catchment using RUSLE and GIS following which high erosion risk areas were to be identified and a soil loss intensity map developed. The choice of the RUSLE model was informed by its widespread use, documentation, ease with which data is extrapolated, capability of quantifying soil erosion factors and that of producing a net estimate of soil loss and finally modeling soil loss over a particular area, (Depountis et al., 2018; Thlakma et al., 2018).

\section{Materials and Methods}

\subsection{Description of the Study Area}

The study was carried out in Maruba dam reservoir catchment, in Machakos County, Kenya (figure 1). Maruba dam reservoir serves as the key source of water for Machakos town and its environment and it is operated by the Machakos Water and Sewerage Company. The town has a projected population of about 210,000 and the water demand has been estimated at $8000 \mathrm{~m}^{3} /$ day. The dam was built in $1950 \mathrm{~s}$ and has a height of $17 \mathrm{~m}$ in addition to a design yield of about $4000 \mathrm{~m}^{3} /$ day. The storage capacity of the dam has reduced over years due to buildup of sediment to nearly $2000 \mathrm{~m}^{3} /$ day. 


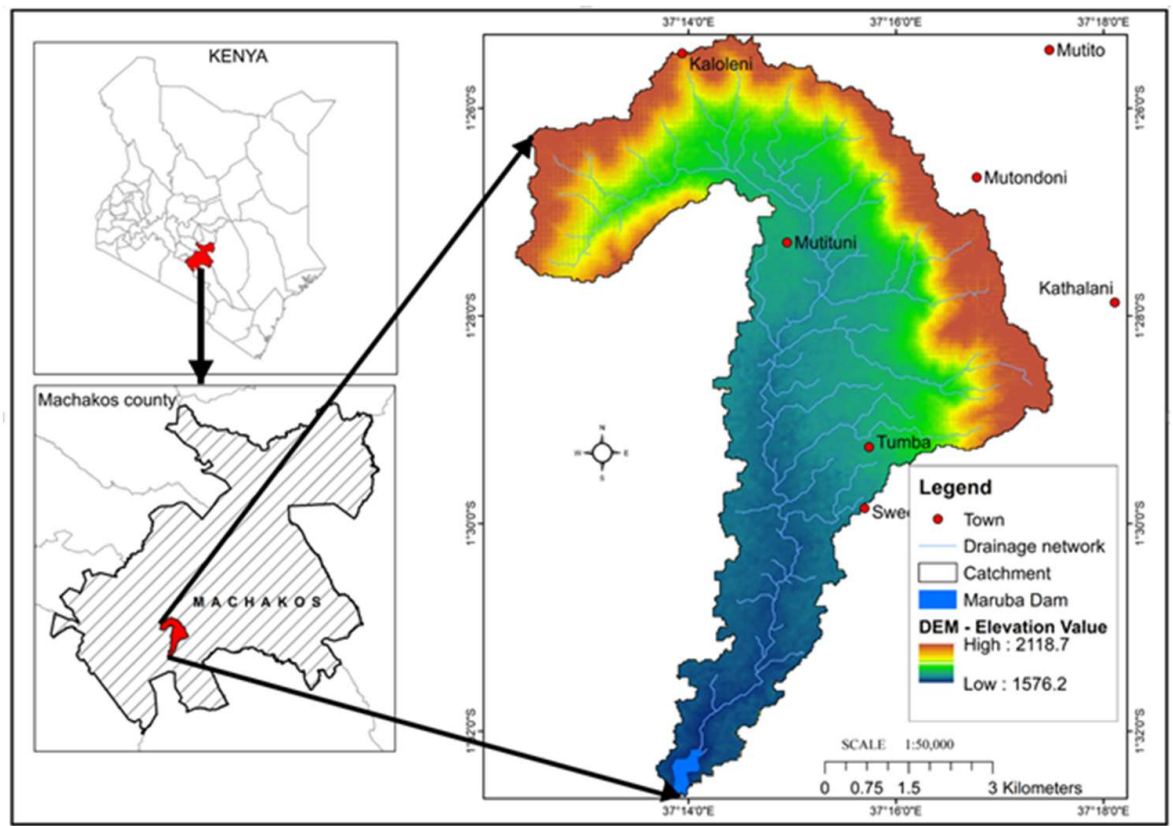

Figure 1: Location of the study area

\subsection{Data Collection}

The methodology adopted for this study was an integration of the revised universal soil loss equation (RUSLE) and geographical information system (GIS) spatial analysis environment, (Angima et al., 2003; Kidane et al., 2019; Rellini et al., 2019). The model utilizes several parameters which were obtained from different sources, (Table 1). Reconnaissance survey indicated that Maruba dam catchment has suffered rapid land use and land cover changes for the last few decades. Therefore, the methodological framework for this study was critical in estimating the loss of soil due to this rapid change in Maruba dam catchment. The model parameters were estimated based on the following data sets: rainfall, digital elevation models (DEM), soil properties, and soil data, (Rellini et al., 2019).

Table 1: Table of datasets and their sources

\begin{tabular}{|c|l|l|l|}
\hline S. No. & \multicolumn{1}{|c|}{ Types of data } & \multicolumn{1}{c|}{ Sources of Data } & \multicolumn{1}{c|}{ Description } \\
\hline 1. & Rainfall data & $\begin{array}{l}\text { Kenya meteorological } \\
\text { department }\end{array}$ & $\begin{array}{l}\text { Average annual rainfall for } \\
30 \text { years }(1990-2019)\end{array}$ \\
\hline 2. & Soil data & $\begin{array}{l}\text { Field collection and laboratory } \\
\text { determination }\end{array}$ & $\begin{array}{l}\text { Soil samples analyzed for } \\
\text { texture, structure, organic } \\
\text { matter and permeability }\end{array}$ \\
\hline 3. & $\begin{array}{l}\text { Digital Elevation Models } \\
\text { (DEM) }\end{array}$ & $\begin{array}{l}\text { RCMRD (Regional Centre for } \\
\text { Mapping of Resources for } \\
\text { Development) }\end{array}$ & SRTM 30m resolution \\
\hline 4. & Satellite images & $\begin{array}{l}\text { USGS } \\
\text { (https://earthexplorer.usgs.gov) }\end{array}$ & $\begin{array}{l}\text { Landsat 8 OLI/TIR of } \\
\text { November 2020 with a } \\
\text { resolution of 30m }\end{array}$ \\
\hline
\end{tabular}

\subsection{Estimation of Soil Loss}

The procedure for estimating soil loss using RUSLE model involves implementing the empirically developed formula in raster based spatial analysis, (Kidane et al., 2019; Rellini et al., 2019). Here, each parameter was calculated using a grid-based criterion after which the model values were multiplied in a raster calculator and the outcome was total soil loss per grid cell, (Renard et al., 1991). The input factors for the RUSLE model are represented as shown in equation (1).

$$
\mathrm{A}=\mathrm{R} \times \mathrm{K} \times \mathrm{LS} \times \mathrm{C} \times \mathrm{P}
$$

Where, $\mathrm{A}=$ spatial average of soil loss computed over a selected period of time $\left(\mathrm{t} \mathrm{ha}^{-1} \mathrm{yr}^{-1}\right), \mathrm{R}=$ rainfall-runoff erosivity factor (MJ mm tha $\left.a^{-1} \mathrm{y}^{-1}\right), \mathrm{K}=$ soil erodibility factor $\left(\mathrm{tha} \mathrm{h} \mathrm{ha} \mathrm{CJJ}^{-1} \mathrm{MJ}^{-1}\right), \mathrm{LS}=$ slope length steepness factor (dimensionless parameter), $\mathrm{C}=$ cover management factor (dimensionless parameter ranging between 0 and 1.5), $\mathrm{P}=$ erosion control (conservation support) practices factor ranging between 0 and 1 . The methodological framework for this study is schematically represented by figure 2 below: 


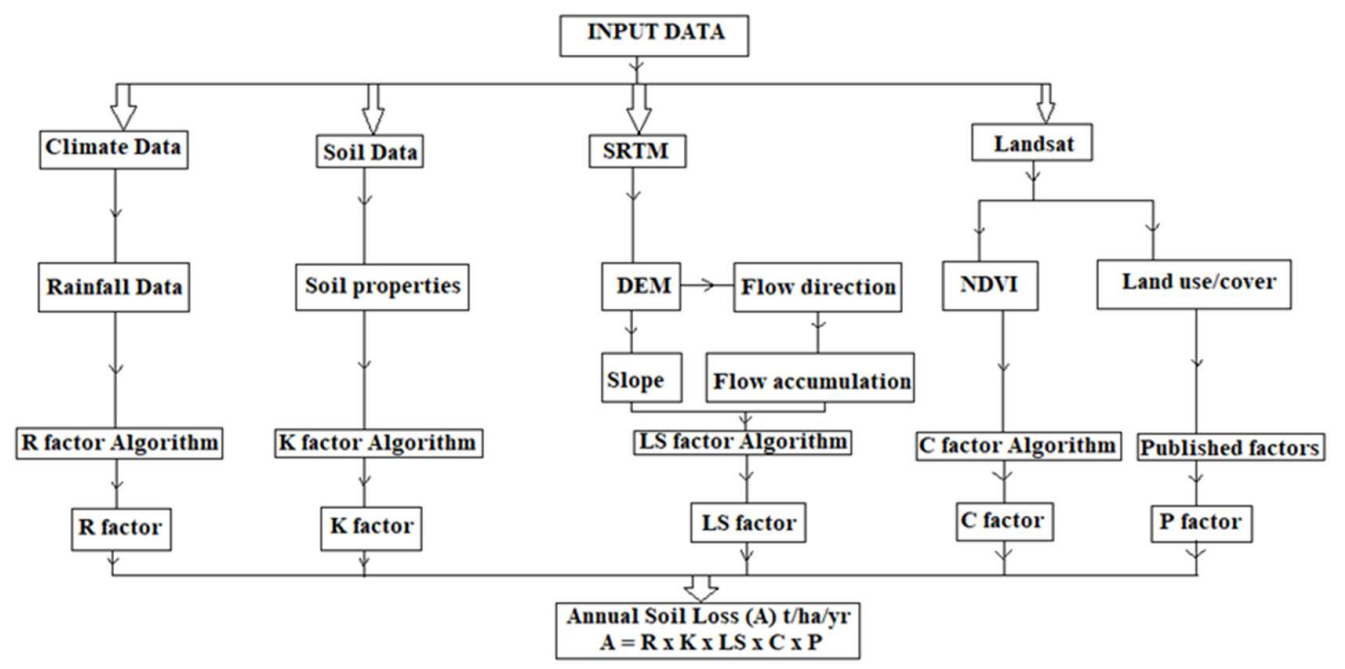

Figure 2: Flow chart of RUSLE methodology

\subsubsection{Estimation of the RUSLE factors}

\section{Rainfall Erosivity Factor (R)}

Rainfall is a critical factor in water erosion processes and its erosive power is defined by rainfall erosivity, (Conforti et al., 2016). $\mathrm{R}$ factor therefore measures the erosive force possessed by rainfall of specific intensity, (Thlakma et al., 2018). In simple terms, it is a measure of how aggressive the rainfall is, (Kidane et al., 2019). The $\mathrm{R}$ factor takes into account the combined effect duration, magnitude and intensity of each rainfall storm, (Wischmeier \& Smith, 1978; Renard et al., 1997; Kidane et al., 2019). R factor may be calculated on storm basis or even a series of storms where the cumulative erosivity effect for a particular period of time is accounted for, (Thlakma et al., 2018). For this study, rainfall data for 30 years (1999 to 2019) for three stations was collected from the Kenya Meteorological Department, Nairobi, Kenya. Continuous raster grids based on 30 year average annual rainfall data were created using geospatial interpolation techniques in geographic information system framework, (Kidane et al., 2019). After the development of rainfall grids, equation ... was used to calculate the rainfall factor in ArcGIS raster calculator. Equation (2) was developed by Kassam et al. (1992) for calculation of R factor for Kenyan situation.

$$
\mathrm{R}=117.6\left(1.00105^{\mathrm{MAR}}\right) \text { for }<2000 \mathrm{~mm}
$$

Where MAR $=$ mean annual rainfall $(\mathrm{mm})$.

\section{Soil Erodibility Factor $(K)$}

The soil erodibility factor $(\mathrm{K})$ measures the inherent susceptibility of soil or even surface material to erosion, (Ayalew, 2015; Ganasri \& Ramesh, 2016; Koirala et al., 2019). The K factor is influenced by the soils' physical and chemical soil properties and which have been reported to experience spatial variation, (Conforti et al., 2016). The main soil parameters which affect the $\mathrm{K}$ factor include soil texture, soil structure, organic matter content and permeability, (Wischmeier \& Smith, 1978; Koirala et al., 2019). Hence, different types of soils have varying degrees of natural resistance and susceptibility to erosion depending on the soil's properties, (Thlakma et al., 2018). Soil erodibilty is described as the resistance to either detachment or transport of soil particles. Therefore, $\mathrm{K}$ factor values reflect the rate at which soil is lost per rainfall erosivity indices, (Gansri \& Ramesh, 2016; Koirala et al., 2019). For this particular study, soil erodibility factors were calculated using the equation (3) developed by (Wischmeier and Smith, 1978). The equation is based on soil texture, particle size distribution, soil structure, organic matter content and permeability.

$$
\mathrm{K}=27.66 \mathrm{~m}^{1.14} * 10^{-8} *(12-\mathrm{a})+0.0043(\mathrm{~b}-2)+0.0033(\mathrm{c}-3)
$$

Where, $\mathrm{K}=$ Soil erodability factor $\left(\right.$ ton $\left.\cdot \mathrm{hr}^{-1} \cdot \mathrm{ha}^{-1} \cdot \mathrm{MJ} \cdot \mathrm{mm}\right), \mathrm{m}=($ Silt $\%+$ Sand $\%) \times(100-$ clay $\%)$, a $=$ percent organic matter, $\mathrm{b}=$ soil structure code: 1) very structured or particulate, 2) fairly structured, 3 ) slightly structured, and 4) solid, $\mathrm{c}=$ soil profile permeability code: 1) rapid, 2) moderate to rapid, 3) moderate, 4) moderate to slow, 5) slow, 6) very slow.

The calculation of $\mathrm{K}$ factor values was based on analyzed data on soil properties where samples were collected between $0-20 \mathrm{~cm}$ depth. The soil samples were a representative the numerous soil types and the varying degree 
of land degradation conditions within the catchment area, (Conforti et al., 2016; Olaniya et al., 2020). Georeferencing of the sampling points was achieved with the use of a global positioning system (GPS) receiver which had a precision of $3 \mathrm{~m}$. Laboratory analysis for determination of soil texture, organic carbon and hydraulic conductivity were determined using standard procedures. The $\mathrm{K}$ factor values were interpolated in GIS framework following which the spatial distribution of soil erodibility was derived.

Ganasri and Ramesh (2016) noted the following with regards to soil types and $\mathrm{K}$ factor values: Clay soils are associated with low values of soil erodibility because they are quite resistant to detaching forces. Likewise, sandy soils have low soil erodibility values because they have high rates of infiltration and reduced levels of runoff and as such sandy particles resist transportability. On the other hand, silt loams have moderate to relatively high soil erodibility values since silt particles suffer moderate detachment, infiltration and transport. Silt soils are reported to have the very high $\mathrm{K}$ values because they crust very readily thereby producing very high rates of runoff and quantities as well.

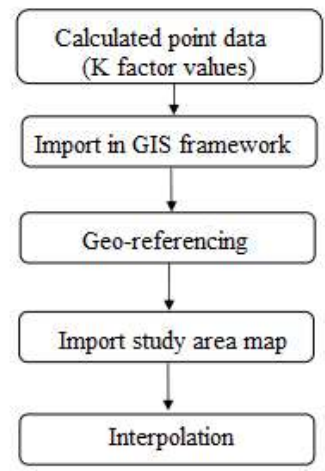

Topographic Factor (LS)

Figure 3: Derivation of the K factor Map

The topographic factor (LS) depicts the topographic effects on erosion and it includes steepness and length of slope which influence the speed of surface runoff, (Conforti et al., 2016; Koirala et al., 2019). The two sub-factors are critical in soil erosion modeling because they aid in calculation of the transport capacity of overland flow, (Ganasri \& Ramesh, 2015; Conforti et al., 2016) and they are determined from DEM, (Koirala et al., 2019). The sub-factors L and S capture the contribution of slope length and slope gradient on erosion respectively, (Renard et al., 1997). The slope length (L) accounts for the slope length effect on soil erosion and it is defined as the distance from the point where overland flow begins to the point where surface gradient reduces to an extent that deposition of erosion material begins or surface runoff water finds its way in a channel which is well defined, (Ganasri \& Ramesh, 2015; Koirala et al., 2019; Tessema et al., 2020). As a consequence, the amount of soil lost per given unit area increases with slope length, (Tessema et al., 2020).

On the other hand, slope steepness (S) accounts for slope steepness effects on soil erosion, (Ganasri \& Ramesh, 2015; Koirala et al., 2019). Erosion effects are more pronounced with increase in slope steepness as compared to increase in slope, (Koirala et al., 2019). This means soil is lost more in highly sloping areas and the worst form of it occurs in slope gradient varying from 10 to 25 percent, (Ganasri \& Ramesh, 2015). Thus, the LS factor is an expression of topographical effects on soil erosion and as such the factor is noted to increase with increase in both sub-factors, (Koirala et al., 2019).

In this study, the topographic factor was computed from the slope and flow accumulation maps, (Karamage et al., 2016). The Shuttle Radar Topography Mission (SRTM) digital elevation model (DEM) for Kenya with a spatial resolution of $30 \mathrm{~m}$ was obtained from the Regional center for mapping of resources and development (RCMRD). The procedure in computing the LS factor involved filling DEM sink using the hydrology too in ArcGIS after which flow direction and flow accumulation were generated, (Karamage et al., 2016; Kogo et al., 2020; Tessema et al., 2020). DEM was also used to compute the surface slope after which the topographic factor was calculated using equation (4).

$$
\mathrm{LS}=\left(\frac{\mathrm{Q}_{\mathrm{a}} \mathrm{M}}{22.13}\right)^{\mathrm{y}} \times\left(0.065+0.045 \times \mathrm{S}_{\mathrm{g}}+0.0065 \times \mathrm{S}_{\mathrm{g}}^{2}\right.
$$

Where, $\mathrm{LS}=$ topographic factor, $\mathrm{Q}_{\mathrm{a}}=$ flow accumulation grid, $\mathrm{Sg}=$ grid slope $(\%), \mathrm{M}=$ grid size (vertical length $\mathrm{x}$ horizontal length), $\mathrm{y}=$ dimensionless exponent which depends on slope steepness and ranges from 0.2 to 0.5 . Wischmeier and Smith (1978) proposed the values of y as follows: 0.5 for slopes greater than $4.5 \%, 0.4$ for slopes between 3 and $4.5 \%, 0.3$ for slopes between 1 and $3 \%$ and 0.1 for slopes less than $1 \%$. 


\section{Land Cover Factor $(C)$}

The land factor reflects the effect of soil cover on soil erosion, (Wischmeier \& Smith, 1978; Renard et al., 1997; Koirala et al., 2019). It is related to land use and land cover changes, (Wischmeier \& Smith, 1997). C factor represents the effect brought about on soil by soil disturbing activities, vegetation, sequence of crops and production level, (Thlakma et al., 2018). Vegetation is ranked second after topography with regards to the risk of soil erosion, (Koirala et al., 2019). Generally, vegetation intercepts rainfall thereby increasing the rates of infiltration in addition to absorbing the energy possessed by rainfall. The range of $\mathrm{C}$ factor values is between 0 and 1 with 0 indicating strong effect in land cover while 1 shows no effect at all.

$\mathrm{C}$ factor for the RUSLE model is computed from different sub-factors such as prior land use, surface cover, canopy cover, surface roughness and soil moisture, (Renard et al., 1997). These sub-factors experience spatial and temporal variation and as such, remote sensed data serves as an important tool for assessing the C- factor. Hence, satellite imagery was used to prepare land use and land cover map. Normalized Difference Vegetation Index (NDVI) is an important indicator which helps in detection and interpretation of vegetation cover, (Kogo et al., 2020). NDVI serves as an indicator for the vegetation vigor and health. Landsat 8 OLI/TIR of November 2020 with a resolution of $30 \mathrm{~m}$ was downloaded from https://earthexplorer.usgs.gov. From these multispectral images, NDVI map was extracted. The $\mathrm{C}$ factor map for the study area was generated using equation 5 in a spatial analyst raster calculator.

Land use and land cover classification of the catchment area was done using supervised classification based on Maximum Likehood Classifier algorithm. Here, six land use and land cover classes were identified and which were verified using ground truth, (Ayalew, 2015). A normalized difference vegetation index (NDVI) map for the catchment was produced. NDVI serves as an indicator for the vegetation vigor and health and it was incorporated in equation (5) following which the C-factor value map for the study area was generated.

\section{Support Practices (P) Factor}

$$
\mathrm{C}=0.1\left(\frac{-\mathrm{NDVI}+1}{2}\right)
$$

Support practices (P) factor is an indication of the rate at which soil is lost from various farmlands, (Thomas et al., 2018; Koirala et al., 2019). P factors reflect the effects brought about by practices which reduce the magnitude and the rate of runoff water and thus reducing erosion amount, (Wischmeier and Smith, 1978; Ganasri \& Ramesh, 2016). The factor gives an account of the specific conservation practices which aim to reduce the erosion potential of runoff water by the manner in which they influence drainage patterns, concentration of runoff, velocity of runoff and hydraulic forces subjected to the soil by runoff, (Ganasri \& Ramesh, 2016; Kogo et al., 2020). P factor values have a range of between 0 and 1 , where a value of 0 shows that there is good facility which resists erosion while 1 shows that there is none, (Thomas et al., 2018; Koirala et al., 2019).

Support practice factor for this study was derived from land use and land cover map in conjunction with the Wischmeier and Smith (1978) methodology (table 2). This methodology involved assigning values to each of land use/land cover class on the basis of the slope after which a P factor map was derived in a GIS framework, (Ayalew, 2015; Kidane et al., 2019; Kogo et al., 2020).

Table 2: P factor values (Source: Wischmeier \& Smith, 1978)

\begin{tabular}{|l|l|c|}
\hline Land use & Percentage slope & P-factor \\
\hline \multirow{3}{*}{$\begin{array}{l}\text { Agriculture } \\
\text { cultivated land) }\end{array}$} & $0.00-5.00$ & 0.10 \\
\cline { 2 - 3 } & $5.00-10.00$ & 0.12 \\
\cline { 2 - 3 } & $10.00-20.00$ & 0.14 \\
\cline { 2 - 3 } & $20.00-30.00$ & 0.19 \\
\cline { 2 - 3 } & $30.00-50.00$ & 0.25 \\
\cline { 2 - 3 } & $50.00-100.00$ & 0.33 \\
\hline Other land use & All & 1.00 \\
\hline
\end{tabular}

\subsubsection{Soil Loss Analysis}

Processing of geospatial data sets was done in ArcGIS where five raster maps for rainfall erosivity, soil erodibility, topographic, land cover and support practice factors were produced, (Thomas et al., 2018). The produced raster maps were then integrated within a geographic information system framework (ArcGIS 10.5) using raster operations and with the use of the RUSLE equation a composite map through which the annual rate of soil erosion could be predicted in t/ha/year was created, (Depountis et al., 2018; Sujatha \& Sridhar, 2018; Koirala et al., 2019). 


\section{Results and Discussions}

\subsection{Rainfall Erosivity Factor}

The rate of soil erosion in Maruba dam catchment is a little bit more sensitive to precipitation. This is evident due to the volumes of sediment impoundment in Maruba dam. The $\mathrm{R}$ factor value ranged from 251 to $254 \mathrm{MJ} \mathrm{mm}$ $\mathrm{ha}^{-1} \mathrm{yr}^{-1}$. The $\mathrm{R}$ factor map shown in figure 4 below shows the spatial distribution of the rainfall erosivity values. The $\mathrm{R}$ factor map show slight variation in $\mathrm{R}$ factor values since the catchment is quite small with an area of 49 $\mathrm{km}^{2}$.

\subsection{Soil Erodibility Factor}

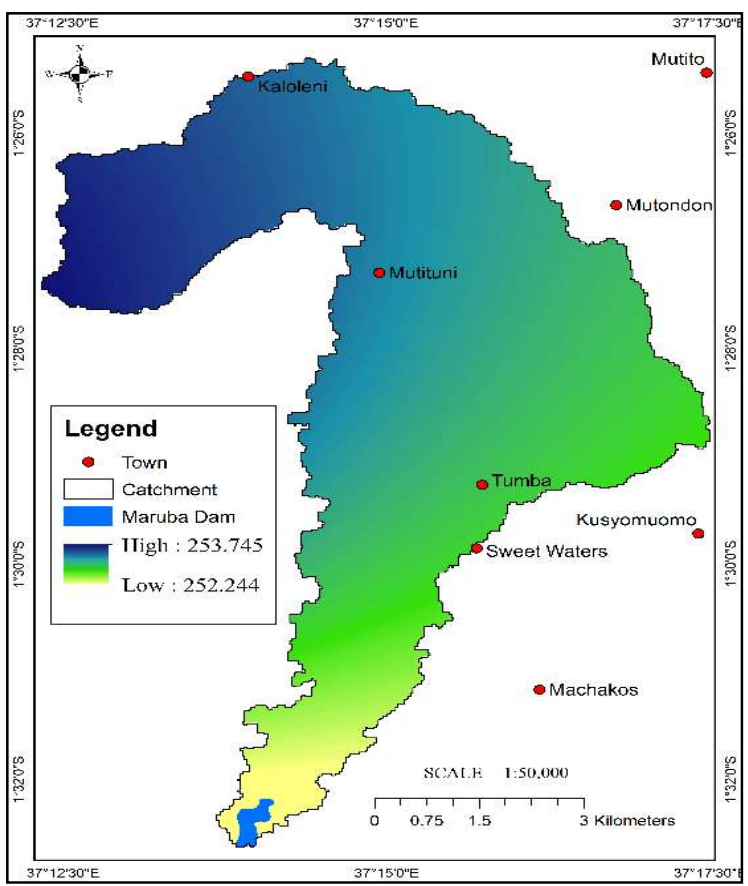

Figure 4: Rainfall Erosivity Factor Map

Soil erodibility measures a soil's resistance to erosive power possessed by rainfall energy and that of runoff. There exists a strong relation between mechanical composition of soils and organic matter content, (Ban et al., 2016). Figure 4 below shows the spatial distribution of the $\mathrm{K}$ factors for entire catchment. Higher soil erodibility factors are indicative of easier detachment while low ones mean that the soil particles are compacted and therefore would require higher detaching forces, (Obiora-Okeke, 2019). The $\mathrm{K}$ values for this study range between 0.0026 and $0.0117 \mathrm{t} \mathrm{ha} \mathrm{h} \mathrm{ha}^{-1} \mathrm{MJ}^{-1} \mathrm{~mm}^{-1}$. The values are generally low which according to Ganasri \& Ramesh (2016) such soils are associated with soils which have low permeability rates, low initial soil moisture content, etc., (Ganasri \& Ramesh, 2016). 


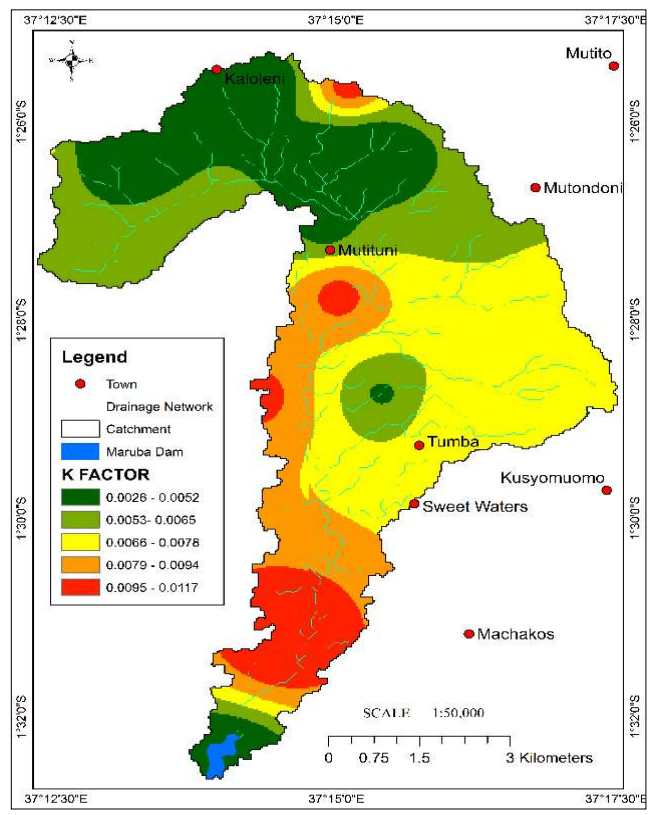

Figure 5: Soil Erodibility Map

\subsection{Topographic Factor (LS)}

The slope gradient of the catchment ranged from 0 to $50 \%$. The slope gradient was classified into six classes. Figure 6 shows that the topographic factor for the study area ranged from $0-384$. Topographic characteristics of a catchment area have a strong influence on the spatial variation of soil loss and deposition. In this regard, the LS factor was noted to increase as flow accumulation and slope increased, (Ganasri \& Ramesh, 2015). High values for LS factor indicate that such areas are characteristic of steep slopes and longer slope lengths. This means that the velocity of surface runoff increases with slope. On the other hand, increased velocity of surface runoff over a longer distance causes more detachment of soil particles. Figure 6 shows that the topographic factor was highest in hilly terrains and along gullies, (Wischmeier \& Smith, 1978).

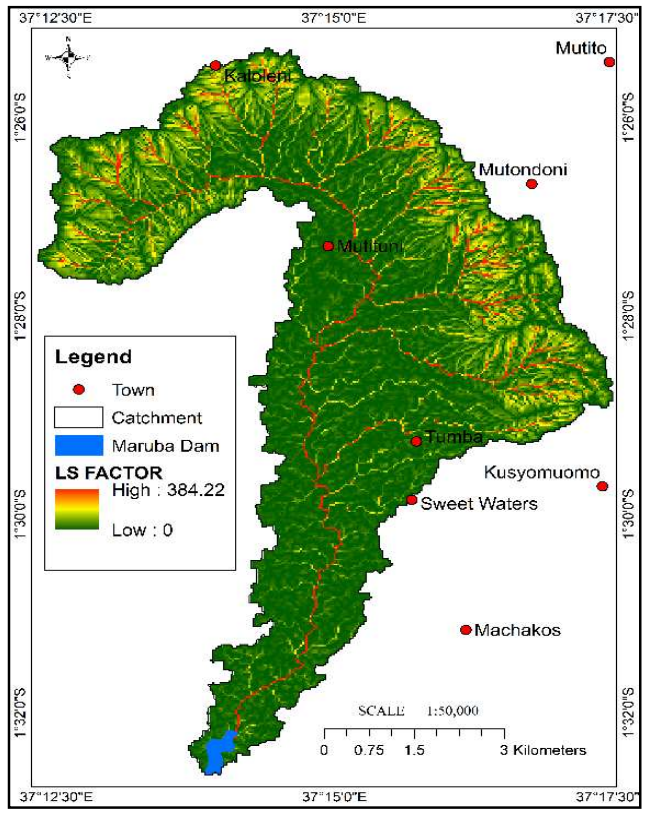

Figure 6: Topographic Factor Map

\subsection{Land Cover Factor (C)}

Land utilization factors such cropping patterns, forests, fallow lands, waste lands among others are better 
understood if information regarding land use is made available as this necessitates planning for development and soil erosion studies, (Ganasri \& Ramesh, 2015). In this regard, $\mathrm{C}$ factor is an indicator of land cover and vegetation management, (Wolka et al., 2015) and its range is between 0 and 1. It is taken as the most important RUSLE factor with regards to reducing soil loss in highly sloping terrains. The factor indicates how effective vegetation cover is with regards to soil erodibility (Obiora-Okeke, 2019). Vegetation reduces the raindrop impact on soil hence reduced detachment of soil particles. Therefore, soil cover by cover plants, mulches, cover crops and crop residues have a protective effect on soils from wind and water erosion and cumulative result is enhanced infiltration and increased soil organic matter. However, land cover varies significantly depending on the forest type, agricultural activities and shrub land among others. Hence, areas which have high $\mathrm{C}$ factor values are indicative of rocky surfaces or open scrub land, (figure 7). According to figure 7, soil erosion is much less in built-up lands and vegetated areas and much higher in bare lands and exposed surfaces.

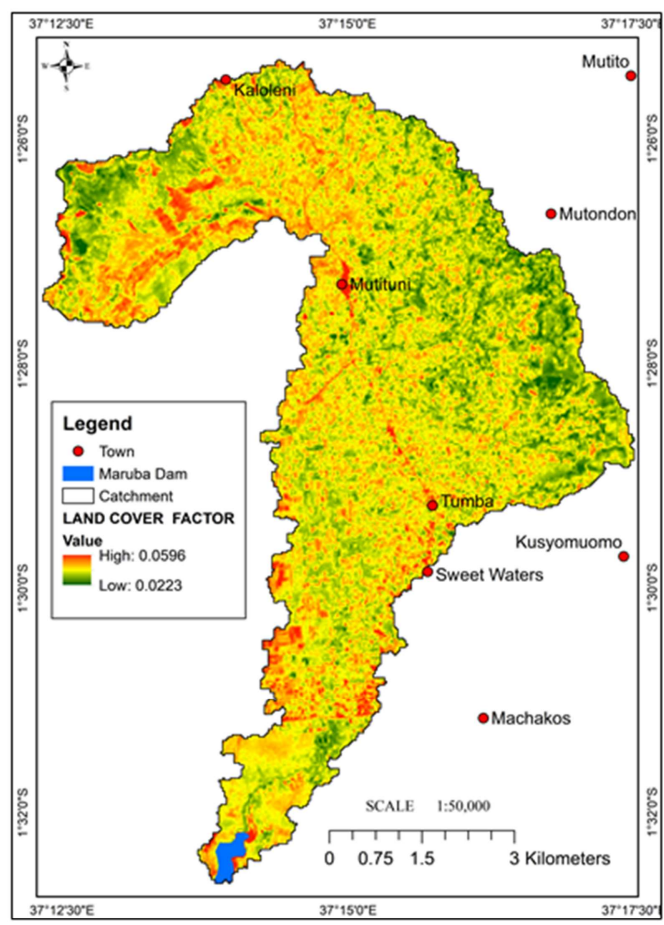

\subsection{Support Practices Factor $(P)$}

Figure 7: Land Cover Factor Map

Soil conservation practices slow down the process of soil erosion by reducing the amount and rate of runoff, (Obiora-Okeke, 2019; Rellini et al., 2019; Kogo et al., 2020). In places where no such practices have been put into place, the soils are very vulnerable to erosion, (Obiora-Okeke, 2019). P factor values ranges from 0 to 1 , where a value that approaches 0 indicates some good conservation practice while a value that approaches 1 is indicative of poor or no conservation practice at all, (Rellini et al., 2019). A combination of land use and land cover classes with slope was used to compute the $\mathrm{P}$ factor upon which the conservation factor map for the catchment was produced. The spatial distribution of the $\mathrm{P}$ factor is shown in figure 7 below. In steep slopes, agricultural activities are accompanied by soil conservation structures and that explains why the $\mathrm{P}$ factor appears to have a high value, (figure $7)$. 


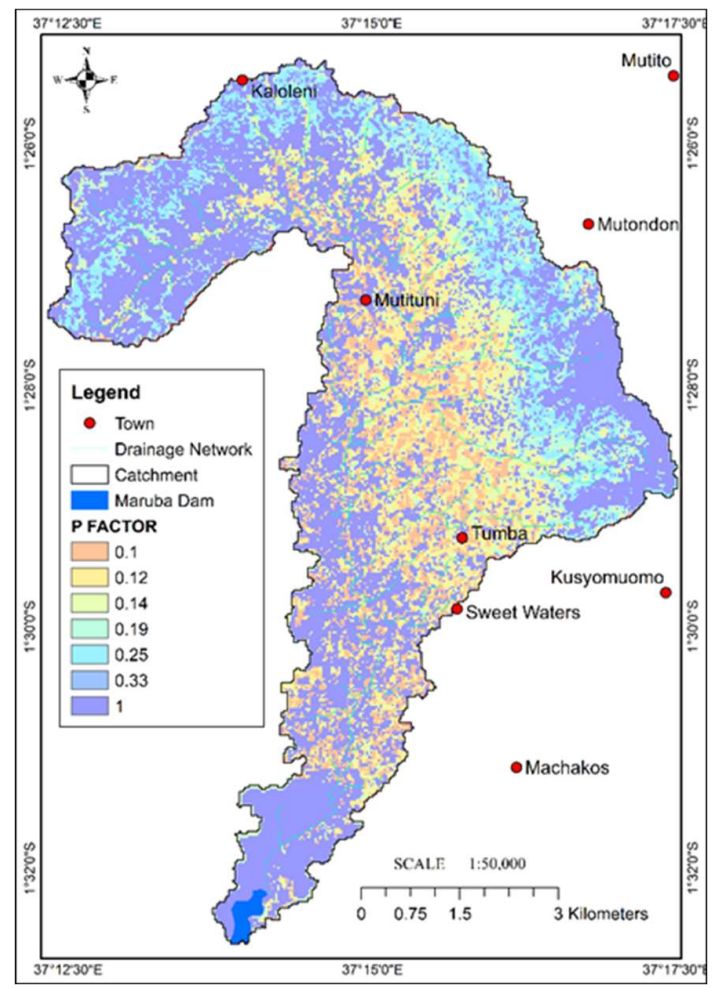

Figure 7: Support practices factor map

\subsection{Spatial Distribution of Soil Loss}

The RUSLE model predicts the amount soil loss on an annual basis as function five parameters: rainfall erosivity $(\mathrm{R})$, soil erodibility (K), topographic factor (LS), land cover management (C), and support practice factor (P). The raster layers of each RUSLE factor were superimposed then multiplied in GIS environment after which soil erosion risk maps for the entire catchment were generated. The soil erosion maps were further subjected to classification where five classes were obtained. These included: slight $(0-2)$, moderate $(2-5)$, high $(5-10)$, very high $(10-$ 15) and extreme $(15-30) \mathrm{t} \mathrm{ha}^{-1} \mathrm{yr}^{-1}$, (table 3). The spatial distribution of soil loss for Maruba dam catchment is given by figure 8 below. According to the figure, the predicted average annual loss of soil ranges from 0 to 29 ton/ha/year. These statistics are indicative of the real existence soil erosion risk in the study area. The spatial distribution as well the soil erosion rates are closed associated with land use and the topography of the catchment. In this regard, soil erosion is prevalent in the highly sloping areas of the catchment. The high population density with the dam catchment piles enormous pressure on land and water resources. Therefore, the vulnerability of soil loss has increased and this requires immediate attention.

Differences in soil loss are brought about by variability of soil erosion contributing factors such as topographic factors, erosivity and erodibility and most importantly land use and land cover, (Kogo et al., 2020). Table 3 shows that $90 \%$ of the catchment experiences moderate soil loss. This shows that soil loss was within the soil loss tolerance of between 5 to $11 \mathrm{t} \mathrm{ha}^{-1} \mathrm{yr}^{1}$, (Mati et al., 2000). Hammad (2009) argued that soils which have depths of less than $100 \mathrm{~cm}$, low content of organic matter (1 to $3 \%$ ) and low aggregate stability should be categorized using the lower limit of soil loss tolerance. The highlighted characteristics by Hammad (2009) apply to soils within Maruba dam catchment. Therefore, the risk of soil loss within the catchment is considered high. Further, the cumulative effect of soil erosion cannot be ignored given its extent over the entire catchment, (Kogo et al., 2020). 


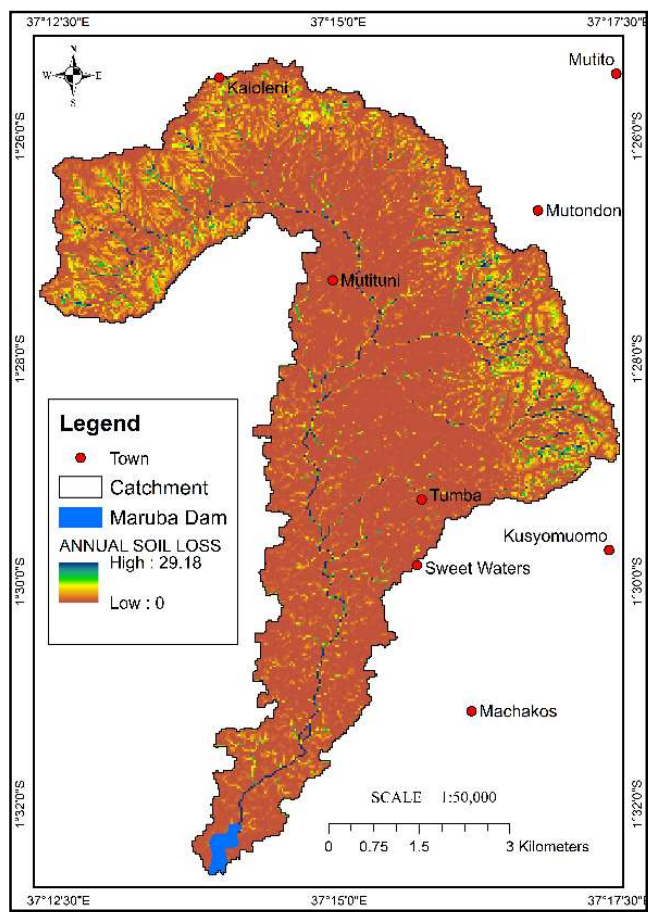

Figure 8: Spatial distribution of soil loss Table 3: Soil loss classes

\begin{tabular}{|l|c|c|}
\hline Erosion Categories & Nuneric Range $\left(\mathbf{t ~ h a}^{-1} \mathbf{y r}^{-\mathbf{1}}\right)$ & Soil Loss Proportions (\%) \\
\hline Very Low & $0-2$ & 78.52 \\
\hline Low & $2-5$ & 11.04 \\
\hline Moderate & $5-10$ & 8.28 \\
\hline High & $10-15$ & 2.14 \\
\hline Very High & $15-20$ & 0.02 \\
\hline Extremely High & $20-30$ & 0.01 \\
\hline & & 100 \\
\hline
\end{tabular}

\section{Conclusions}

Evaluation of soil loss within catchments is an important discourse which would help in planning for prevention measures in order to foster sustainable use of land. The use of an empirical approach which comprised of the RUSLE model integrated with geographical information system was use to estimate the average annual loss of soil. The study singled geospatial techniques and remote sensing as key methodologies in the derivation of the RUSLE model factors at an appreciable cost and in a practical manner considering the constraints in data availability within the catchment. Through this methodology, vulnerable areas to soil loss within the catchment were identified. The study identified soil erosion as a major challenge in Maruba dam catchment $\left(0-29 \mathrm{t} \mathrm{ha}^{-1} \mathrm{yr}^{-}\right.$ ${ }^{1}$ ). The severity of soil erosion in dam catchment was brought to light by this study (table 3 ). The spatial distribution of soil erosion in the catchment area is strongly related to the use of land and topography. The health of the catchment was noted to be compromised by the undulating nature of the terrain in addition to the unsustainable land uses. Since land use and land cover is an important consideration in soil erosion studies, having the right information on land use changes and land cover features would be a good entry point for fast-tracking soil and water conservation measures. Consequently, establishing the slope length and slope steepness of the entire catchment would inform the design of various soil and water conservation structures. Soil erosion was found to be high in the catchment where different terrain modifications exist (figure 8). The health of the catchment may be improved by adopting effective ways of controlling soil erosion such as grass ways, adoption of conservation practices and use of soil conservation structures such as terraces and contours among others. 


\section{Recommendations}

The predicted quantity of soil loss and its spatial variation is an important breakthrough in developing a comprehensive and a sustainable conservation plan for Maruba dam catchment. Priority should be given to areas which have high rates of soil loss especially around hilly terrains. Terrain modifications must be made sustainable as a way of restoring the health of the catchment in moderate erosion hazard areas.

\section{References}

Angima, S., Stott, D., O’Neill, M., Ong, C., \& Weesies, G. (2003), "Soil Erosion Prediction Using RUSLE for Central Kenyan Highland Conditions", Agricultural, Ecosystems and Environment 97, 295-308.

Ayalew, G. (2015), “A Geographic information system based soil loss and sediment estimation in Zingin watershed for conservation planning, highlands of Ethiopia”, International Journal of Science, Technology and Society 3(1), $28-35$.

Ban, K.J., Yu, I. \& Jeong, S. (2016), "Estimation of Soil Erosion Using RUSLE Model and GIS Techniques for Conservation Planning from Kulekhani Reservoir Catchment, Nepal”, J. Korean Soc. Hazard Mitig. 16(3), $323-330$

Benavidez, R., Jackson, B, Maxwell, D \& Norton, K. (2018), "A review of the (Revised) Universal Soil Loss Equation (R)USLE): with a view to increasing its global applicability and improving soil loss estimates", Hydrol. Earth Syst. Sci. 22, 6059-6086.

Beyene, A.A. (2019), "Soil Erosion Risk Assessment in Nashe Dam Reservoir Using Remote Sensing, GIS and RUSLE Model Techniques in Horro Guduru Wollega Zone, Oromia Region, Ethiopia" Journal of Civil, Construction and Environmental Engineering 4(1), 1 - 18.

Biamah, E.K. (1997), “Conservation of cropland: Structural measures”, In Soil and Water Conservation Manual for Kenya. Thomas, B.D., Encksscn, A., Grunder, M. and Mburu, K.J. (eds). Soil and Water Conservation Branch, Ministry of Agriculture, Kenya.

Conforti, M., Buttafuoco, G., Rago, V., Aucelli, C.P.P., Robustelli, G., \& Scarciglia, F. (2016), "Soil loss assessment in the Turbolo catchment (Calabria, Italy)", Journal of Maps 12(5), 815 - 825.

Depountis, N., Vidali, M., Katerina, K. \& Sabatakakis, N. (2018), “Soil erosion prediction at the water reservoir's basin of Pineios dam, Western Greece, using the Revised Universal Soil Loss Equation (RUSLE) and GIS", WSEAS Transactions on Environment and Development, 14, 457 - 463.

Dregne, H.E. (1990), "Erosion and soil productivity in Africa”, J. Soil Water Conserv., 45, 431 - 436.

Efthimiou, N., Lykoudi, E. \& Karavitis, C. (2014), "Soil erosion assessment using the RUSLE model and GIS", European Water 47, 15 - 30.

Fleitmann, D., Dunbar, B.R., McCulloch, M., Mudelsee, M., Vuille, M., McClanahan, R.T., Cole, E.J. \& Eggins, S. (2007), "East African soil erosion recorded in a 300 year old coral colony from Kenya", Geophysical Research Letters 34, 1 - 5.

Fwamba, S.W., China, S.S. \& Masibayi, N.E. (2017), "Estimation of Spatial Distribution of Potential Soil Erosion Risk in Isiukhu River Catchment, Kakamega County, Kenya”, International Journal of Engineering Research \& Technology 6(7), $159-163$.

Ganasri, P.B. \& Ramesh, H. (2016), “Assessment of soil erosion by RUSLE model using remote sensing and GIS - A case study of Nethravathi Basin”, Geoscience Frontiers 7, 953 - 961.

Gelagay, S.H. \& Minale, S.A. (2016), "Soil loss estimation using GIS and Remote sensing techniques: A case of Koga watershed, Northwestern Ethiopia”, International Soil and Water Conservation Research 4, 126 136.

Girmay, G, Moges, A. \& Muluneh, A. (2020), "Estimation of soil loss rate using the USLE model for Agewmariayam Watershed, northern Ethiopia", Journal of Agric. \& Food Security 9(9), 1 - 12.

Gitas, L.Z, Douros, K., Minakou, C. Silleos, G.N. \& Karydas, C.G. (2009), "Multi-temporal soil erosion risk assessment in N. Chalkidiki using a modified USLE raster model”, EARSeL eProceedings 8, 40 - 52.

Hammad, A.A. (2009), "Watershed erosion risk assessment and management utilizing revised universal soil loss equation-geographic information systems in the Mediterranean environments", Water and Environment Journal, $1-14$. 
Kassam, H.A., Velthuizen, T.H., Mitchell, B.J.A., Fischer, W.G. \& Shah, M.M. (1992), “Agro-Ecological Land Resources Assessment for Agricultural Development Planning”, A Case Study of Kenya Resources Data Base and Land Productivity. Technical Annex 2, Soil Erosion and Productivity.

Karamage, F., Zhang, C., Kayiranga,A., Shao, H., Fang, X., Ndayisaba, F., Nahayo, L., Mupenzi, C. \& Tian, G. (2016), "USLE-Based Assessment of Soil Erosion by Water in the Nyabarongo River Catchment, Rwanda" International Journal of Environmental Research and Public Health 13, 1 - 16.

Kidane, M., Bezie, A., Kesete, N. \& Tolessa, T. (2019), "The impact of land use and land cover (LULC) dynamics on soil erosion and sediment yield in Ethiopia", Heliyon 5, 1- 13.

Kogo, B.K., Kumar, L. \& Koech, R. (2020), "Impact of Land Use/Cover Changes on Soil Erosion in Western Kenya", Sustainability 12, 1 - 17.

Koirala, P., Thakuri, S., Joshi, S. \& Chauhan, R. (2019), "Estimation of Soil Erosion in Nepal Using a RUSLE Modeling and Geospatial Tool”, Geosciences 9, 1 - 19.

Merritt, S.W., Letcher, A.R. \& Jakeman, J.A. (2003), "A review of erosion and sediment transport models", Environmental Modelling \& Software 18, 761 - 799.

Obiora-Okeke, A.O. (2019), "Erosion Mapping Using Revised Universal Soil Loss Equation Model and Geographic Information System: A Case Study of Okitipupa, Nigeria", European Journal of Engineering and Technology 7(4), $73-80$.

Onyando, O.J., Kisoyan, P. \& Chemilil, M.C. (2005), "Estimation of Potential Soil Erosion for River Perkerra Catchment in Kenya", Water Resources Management 19, 133 - 143.

Panagos, P., Borrelli, P., Poesen, J., Ballabio, C., Lugato, E., Meusburger, K., Montanarella, L. \& Alewell, C. (2015), "The new assessment of soil loss by water erosion in Europe" Environmental Science \& Policy 54, $438-447$

Rellini, I., Scopesi, C., Olivari, S., Firpo, M. \& Maerker, M. (2019), “Assessment of soil erosion risk in a typical Mediterranean environment using a high resolution RUSLE approach (Portofino promontory, NW-Italy)", Journal of Maps 15(2), 356 - 362.

Renard, K., Foster, G. Weesies, G., Mc Cool, D. \& Yoder, D. (1997), “Predicting soil erosion by water”, A guide to conservation planning with the Revised Universal Soil Loss Equation (RUSLE), USDA, Agriculture Handbook No.703. United States Government Printing Office, Washington, DC. 384.

Sujatha, R.E \& Sridhar, V. (2018), "Spatial Prediction of Erosion Risk of a Small Mountainous Watershed Using RUSLE: A Case-Study of the Palar Sub-Watershed in Kodaikanal, South India”, Water 10, 1 - 17.

Tessema, M.Y., Jasinska, J., Yadeta, L.T., Switoniak, M., Puchalka,R. \& Gebregeorgis, E.G. (2020), "Soil Loss Estimation for Conservation Planning in the Welmel Watershed of the Genale Dawa Basin, Ethiopia", Agronomy 10, 1 - 19.

Thomas, J., Joseph, S. \& Thrivikramji, P.K. (2018), "Assessment of soil erosion in a tropical mountain river basin of the southern Western Ghats, India using RUSLE and GIS", Geoscience Frontiers 9, 893 - 906.

Wolka, K., Tadesse, H., Garedew, E. and Yimer, F. (2015), "Soil erosion risk assessment in the Chaleleka wetland watershed, Central Rift Valley of Ethiopia”, Environmental Systems Research 4(5), 1 -12 